\title{
Is VATS Bullectomy and Pleurectomy an Effective Method for the Management of Spontaneous Pneumothorax?
}

\author{
Ramzi A. Addas, Farid M. Shamji, Sudhir R. Sundaresan, Patrick James Villeneuve, \\ Andrew J. E. Seely, Sebastien Gilbert, Donna E. Maziak \\ Department of Thoracic Surgery, General Hospital, Ottawa, Canada \\ Email: ramziaddas@yahoo.com
}

Received 28 July 2016; accepted 27 August 2016; published 30 August 2016

Copyright (C) 2016 by authors and Scientific Research Publishing Inc.

This work is licensed under the Creative Commons Attribution International License (CC BY). http://creativecommons.org/licenses/by/4.0/

(c) (i) Open Access

\begin{abstract}
Spontaneous pneumothorax, primary or secondary, is a common medical emergency for which specific indications for surgical intervention are well defined in selected patients. The traditional surgical approach has been by limited thoracotomy using axillary or posterolateral incision. With the advent of video-assisted minimally invasive technique in the last 20 years the traditional approach is infrequently used. The definitive operation to prevent recurrent pneumothorax by surgical approach requires bullectomy and parietal pleurectomy. The recurrence rate after the traditional open surgical approach has been low at $<2 \%$. On the other hand, video-assisted thoracoscopic surgery, although better tolerated has a higher recurrence rate at $5 \%$ [1]. Information on post-operative morbidity and mortality are lacking. For this reason, we have reviewed our experience at one institution on the outcome of the VATS approach. We found that prolonged postoperative air leak is the most common complication and cigarette smoking remains an important associated factor.
\end{abstract}

Keywords

Bullectomy, Pleurectomy, Thoracoscopic, Morbidity

\section{Introduction}

Video Assisted Thoracic Surgery (VATS) is considered the gold standard surgical technique for the treatment of pneumothorax. To resect blebs or bullae and to achieve satisfactory pleurodesis, several techniques have been described. Minimally invasive technique using staplers to remove bullous parenchyma is the popular method by

How to cite this paper: Addas, R.A., Shamji, F.M., Sundaresan, S.R., Villeneuve, P.J., Seely, A.J.E., Gilbert, S. and Maziak, D.E. (2016) Is VATS Bullectomy and Pleurectomy an Effective Method for the Management of Spontaneous Pneumothorax? Open Journal of Thoracic Surgery, 6, 25-31. http://dx.doi.org/10.4236/ojts.2016.63005 
the majority of thoracic surgeons. Other techniques to perform bullectomy include endoscopic suturing [2] [3]; endoloop ligation [2] [4] and cautery [5] [6] have been described in the literature. The same is true for pleurodesis as there are different ways described including Talc poudrage [7] [8], pleural abrasion [5] [9] [10], partial pleurectomy [6] [11] [12] and pleural argon beam coagulation [13]. There are no studies comparing these different ways of pleurodesis to decide which is better and it remains a department preference in choosing which method. Published studies regarding post-operative morbidity and mortality are lacking. We decided to review our current morbidity and mortality using VATS for the management of primary spontaneous pneumothorax in order to better understand the complications of this procedure, identify any risk factors for complications and see if there is any way for avoiding them.

\section{Methods}

\subsection{Patients}

From 2008 to 2014, 161 patients required bullectomy and pleurectomy by open or VATS due to pneumothoraces at the Ottawa Hospital, Canada. Inclusion criteria for our study were any patient that had a spontaneous recurrent pneumothorax, first tension spontaneous pneumothorax and first pneumothorax associated with prolonged air leak (defined as air leak more than five days) and were treated with VATS approach. Exclusion criteria were patients with secondary pneumothoraces treated with VATS bullectomy and pleurectomy or those who underwent a thoracotomy. The operations were performed by one of six surgeons in the department of Thoracic surgery at the Ottawa Hospital. Preoperative investigations included blood work, chest radiographs and a computed tomographic scan of the thorax in the majority of the cases (some of the patients were taken to the operating room without a CT chest). Data was collected retrospectively for all patients and included a detailed history, age, sex, smoking habits, comorbidities, treatment modalities, and surgical details. The postoperative variables assessed included postoperative complications, duration of chest tube drainage, length of hospital stay as well as a follow up for the patients up to 2 years.

\subsection{Operative Procedures and Management}

\subsubsection{Video-Assisted Thoracoscopic (VATS) Bullectomy and Pleurectomy}

The operations were performed under general anesthesia; lung isolation was achieved by using a double lumen intubation. A $1-\mathrm{cm}$ incision was performed above the diaphragm level which is used as the camera port. The camera is inserted through that port and a thorough inspection is performed. Two further 1-cm incisions anterior and posterior to the tip of the scapula in the fifth intercostal spaceis performed. If blebs or bullaes were found, they were grasped and excised with an endo GIA stapling device with either a single or multiple fires. Partial pleurectomy was then performed by incising the parietal pleura starting at the level of the anterior trocar up to the level of the second rib and back to the level of the posterior trocar. A grasper is used to peel off the parietal pleura. An air leak test was performed under a pressure loading of $20 \mathrm{~cm} \mathrm{H}_{2} \mathrm{O}$. Two chest tubes were placed through the port sites.

\subsubsection{Analgesia}

After the operation, patients were extubated in the operating room and transferred to the recovery room. A perioperative intercostal nerve block was used in addition to patient-controlled analgesia (PCA) system after the operation. This was continued until oral analgesia was commenced on as and when needed.

\subsubsection{Postoperative}

Continuous suction is applied for the first 48 hours. Chest tubes were removed when the underlying lung was fully expanded with no residual air leak and minimal fluid drainage. Patients were discharged from the hospital when they were fully mobile and when their pain was controlled by oral analgesia.

\subsubsection{Follow-Up}

Patients were seen 3 to 4 weeks post-operatively unless if they were discharged from the hospital with a chest tube attached to a pneumostat due to prolonged air leak, in that case they were seen one week after discharge. Chest $\mathrm{X}$ rays were performed at all visits. On follow-up examination, patients were assessed for any signs or symptoms or radiologic features suggesting recurrent pneumothorax. Assessment of wound healing as well as 
Information regarding complications was also obtained.

\subsubsection{Statistical Analysis}

All patients details were interred in the Standardized Monitoring of Post-Operative Morbidity and Mortality for the Evaluation of Thoracic Surgical Quality TSQIC program, a data base system including names, date of birth, reason for admission, elective of urgent surgery, the type of surgery and any complications either during the admission or later after discharge.

\section{Results}

\subsection{Patient Characteristics}

All 161 patients were studied in this prospective review. One hundred and thirty-four underwent VATS bullectomy and pleurectomy for recurrent spontaneous pneumothorax. Average age was 33.8 (range 16 - 63). There were 96 male and 38 female patients. Comorbidities are listed in (Table 1). There were 97 (72.4\%) active smokers (Table 2). Number of recurrences varied from patient to another (Table 3). All patients presented to emergency department complaining of symptoms including shortness of breath (SOB), cough and/or chest pain lasting from a few hours to few days with different severities. Chest X ray and/or CT scan were performed preoperatively and confirmed the presence of a pneumothorax. Indications for treatment were recurrent spontaneous pneumothorax, prolonged air leak or a first time tension pneumothorax. The presence or absence of blebs or bullaes didn't change our decision to perform the procedure. Patients with secondary pneumothoraces or those who underwent a thoracotomy were excluded.

Table 1. Comorbidities.

\begin{tabular}{ccc}
\hline Comorbidity & Number of patients \\
\hline Hypertension & 6 \\
Obesity & 1 \\
Diabetes & 1 \\
Asthma & 2 \\
Hypercholesterolemia & 1 \\
CAD & 1 \\
GERD & 1 \\
Atrial fibrillation & 2 \\
Polio & 1 \\
Scoliosis & 1 \\
TIA & 1 \\
Osteochondromatosis & 1 \\
Cerebral palsy & 1 \\
Lymphoma & 1 \\
\hline
\end{tabular}

Table 2. Smoking.

\begin{tabular}{ccc}
\hline Smoking & Number of patients \\
\hline Active & 97 \\
Never & 13 \\
Ex-smoker & 24 \\
\hline
\end{tabular}




\subsection{Operative Details}

All patients underwent bullectomy and pleurectomy. Bullectomy was performed in all patients, even when the bleb or bullae were not found, a wedge resection of the apex of the upper lobe was performed. There were no unpleasant events. The blebs and/or bullae were found in 112 (83.5\%) patient. Average blood loss was less than $100 \mathrm{~mL}$ in 129 (96\%) of the cases. Air leak testing before closure was satisfactory in all cases. All specimens were sent for pathological analysis. There was no correlation found between the pathological result and the occurrence of complications.

\subsection{Postoperative Details}

The average hospital stay was 4.6 days (range from 2 to 21). The complication rate was 32\%. This includes (Table 4) prolonged air leak $(15.6 \%, n=21)$, recurrent pneumothorax $(7.4 \%, n=10)$, empyema $(3.7 \%, n=5)$, wound infection $(1.4 \%, n=2)$, pleural effusion $(1.4 \%, n=2)$, subcutaneous emphysema, hemothorax, atrial arrhythmia ( $0.7 \%, \mathrm{n}=1$ for each). Regarding the recurrent pneumothoraces 5 of them required readmission and insertion of chest tube and performance of chemical pleurodesis, three required re-operations and 2 required only observation. Smoking was found to be a risk factor for post-operative complications. Ninety-seven patients were active smokers and 24 were ex-smokers. Sixteen of the 21 patients who had prolonged air leak were active smokers (76\%) and eight of the 10 patients who had pneumothorax were active smokers (80\%). For those patients who have air leak, the majority $(n=18)$ were sent home with their chest tube attached to a pneumostat and they were seen regularly in the clinic for follow up and the remaining three remained in the hospital till the air leak was stopped. The chest tubes were removed when there were no more air leak and the lung was fully expanded on chest X-ray. Pathological analysis of the specimens didn't show any correlation with complications.

On follow up, 118 (88\%) patients were followed up to 2 years post operatively and 16 patients didn't show up in clinic. Follow up was ranged from minimally one time to maximum four times for a patient depending on if the recovery was straight forward or there was a complication (mainly the prolonged air leak for chest tube removal). Amongst those who were followed 65.2\% $(n=77)$ were satisfied and they presented with no problems. Eighteen patients were discharged from the hospital with chest tubes because of having a prolonged air leak and

Table 3. Number of recurrences.

\begin{tabular}{ccc}
\hline Number of episodes & Number of patients \\
\hline 1 & 65 \\
2 & 55 \\
3 & 8 \\
4 & 3 \\
\hline
\end{tabular}

Table 4. Post-operative complications.

\begin{tabular}{cc}
\hline Complications & Number of patients (\%) \\
\hline Prolonged air leak & $21(15.6 \%)$ \\
Pneumothorax & $10(7.4 \%)$ \\
Empyema & $5(3.7 \%)$ \\
Pneumonia & $4(2.9 \%)$ \\
Pleural effusion & $2(1.4 \%)$ \\
Wound infection & $2(1.4 \%)$ \\
Subcutaneous emphysema & $1(0.7 \%)$ \\
Atrial fibrillation & $1(0.7 \%)$ \\
Hemothorax & $1(0.7 \%)$ \\
\hline
\end{tabular}


they were followed for that reason, chest tubes were removed when there were no more air leak and the lung was fully expanded on chest X-ray. Nineteen patients (16\%) complained of neuropathic pain which was controlled with oral analgesics and 6 patients (5\%) were still complaining of mild dyspnea on exertion.

\section{Discussion}

Spontaneous pneumothorax (SP) is one of the common problems that the thoracic surgeon face in his or her practice. The rate of recurrence is $20 \%$ after a first episode, $60 \%$ after a second, and $80 \%$ after a third [14]. When spontaneous pneumothorax occurs, it is initially treated by chest tube insertion. Surgery is reserved for cases of recurrence or prolonged air leak. It is also considered when pneumothorax occurs in persons with highrisk occupations, such as deep sea divers or airline pilots, patients with tension pneumothorax or a hemopneumothorax. In these cases, it might be scheduled as well to treat the first episode in order to prevent recurrences [15].

The traditional operation was by limited thoracotomy using axillary or posterolateral approach. Currently, VATS has been increasingly used. There was always a controversy regarding the best treatment, either to manage surgically by open or VATS techniques.

Evidence from randomized controlled trials regarding the advantages associated with VATS for the treatment of pneumothorax seems to be similar for other advantages associated with other minimally invasive thoracic surgeries for other reasons. Most of these studies reported less surgery time, lower use of pain medication, and lower length of hospital stay [16].

Horio et al. found that patients operated on with VATS had higher recurrences compared to patients operated on with thoracotomy. They suggested that these differences could be explained by undetected bullae in the VATS group [17]. Compared to thoracotomy, air leakage tests are more technically challenging during VATS.

Other authors have also recommended wedge resection of the apex in all cases [18] even if the bullae or bleb is not found. Wedging of the lung apex will lead to the creation of inflammation that leads to adhesions between the lung and the thoracic wall.

In a recent multicenter cohort study, they reported successful video assisted thoracic surgery for pneumothorax in 714 patients over a period of two years [19]. Hatz et al. reported excellent short and long term results comparable with thoracotomy [20].

In a review about the recurrence rate of pneumothorax with randomized and non-randomized trials, Barker et al. report that the recurrence of pneumothorax, when the same pleurodesis procedure is performed, is four-fold increased after VATS approaches rather than open approaches [21]. Different results were previously published by Sawada et al. who did not observe a statistical difference between videothoracoscopy and thoracotomy [22]. In our review the rate of recurrent pneumothoraces was $7.4 \%$.

In the literature review there were some postoperative cases of death reported [23]. They were not consequences of VATS technique, but they were directly correlated to the poor preoperative conditions of the patients. In our study there were no death reported.

Bleeding requiring reoperation has been reported by some authors [2] [3], but the source of blood loss was undetectable in the majority of the cases. In our experience there were one hemothorax which subsided by its own and didn't require surgical intervention.

It must be underlined that, besides cases of re-operation, all authors report prolonged air leak, which is the most common postoperative complication. Other morbidities reported in literature are: pneumonia, atelectasis, needing of mechanical ventilation, wound infections, empyema, pleural effusion, ARDS and Horner's syndrome [24] [25].

Uramoto et al. [26] reported factors that predict recurrence. Smoking cessation has been associated with a decreased risk of recurrent SP over a follow-up period of several years. Second, the postoperative recurrence rate was higher in patients with comorbidities than in those without. Third, a history of previous surgery for ipsilateral SP was associated with a higher rate of recurrence. Finally, the postoperative recurrence rate was higher in the patients who underwent hand stitching for blebs than those who underwent device-driven repair [26].

In a recent review jean-Philippe Delpy et al. on 7647 patients in France hospitals to detect the prognostic factors influencing postoperative complications for spontaneous pneumothorax [27], they found that factors associated with the occurrence of respiratory complications (which are defined as atelectasis, pneumonia, empyema, prolonged ventilation, acute respiratory distress syndrome and prolonged air leaks) are male gender, patients older than 33 years, smokers, ASA score of $\geq 2$ and patients with a history of pulmonary disease, coronary artery 
disease, peripheral artery disease and thoracic surgery. Respiratory complications also occurred more frequently on the right side. The median time to recurrence was 3 months (range: 1 - 76 months).

To evaluate the quality of life after surgical treatment of pneumothorax Ben-Nun et al. compared VATS and limited thoracotomy. They observed that patients in the thoracotomy group needed significantly higher doses of narcotic analgesia for a longer period than patients in the VATS group [10]. Similarly Balduyck et al. in a recent prospective study have demonstrated that VATS has an improved thoracic pain evolution than antero-lateral thoracotomy. They also report a significant difference one month postoperatively between VATS and open surgery in physical, role and cognitive functioning and dyspnea in favor of VATS.

The recurrence rate after VATS treatment for pneumothorax was very low (between $0 \%$ and $5.8 \%$ ) [12].

Chronic pain and chest wall paresthesia one year after the procedure have been reported in about $21 \%$ of the patients [9] [28]. Particularly in those who underwent pleurectomy. In order to avoid these complications, Jutley et al. [29] propose the uniportal VATS technique, but the study is limited by the short follow up and by the small number of cases. Chan et al. have suggested the use of needle scopic instruments which, compared with the conventional ones, reduce the residual neuralgia [14]. Long-term results of VATS treatment of pneumothorax are limited.

\section{Conclusion}

VATS bullectomy and pleurectomy is now the preferred surgical approach for treatment of recurrent spontaneous pneumothorax with a reasonable low recurrence rate. Prolonged air leak and the recurrence of pneumothorax are the most common post-operative complication. Smoking was found to be a risk factor for post-operative complications and therefore smoking cessation is important in improving outcome. Further studies with prospective data collection are needed to verify our results.

\section{References}

[1] MacDuff, A., Arnold, A. and Harvey, J. (2010) Management of Spontaneous Pneumothorax: British Thoracic Society Pleural Disease Guideline 2010. Thorax, 65, ii18-ii31. http://dx.doi.org/10.1136/thx.2010.136986

[2] Yim, A.P.C. and Liu, H.P. (1997) Video-Assisted Thoracoscopic Management of Primary Spontaneous Pneumothorax. SurgLaparoscEndosc, 7, 236-240. http://dx.doi.org/10.1097/00019509-199706000-00012

[3] Liu, H.P., Yim, A.P.C., Izzat, B.M., Lin, P.J. and Chang, C.H. (1999) Thoracoscopic Surgery for Spontaneous Pneumothorax. World Journal of Surgery, 23, 1133-1136. http://dx.doi.org/10.1007/s002689900636

[4] Menconi, G.F., Melfi, F.M., Mussi, A., et al. (1998) Treatment by VATS of Giant Bullous Emphysema: Results. European Journal Cardio-Thoracic Surgery, 131, 66-70. http://dx.doi.org/10.1016/S1010-7940(97)00294-7

[5] Naunhein, K.S., Mack, M.J., Hazelrigg, S.R., et al. (1995) Safety and Efficacy of Video-Assisted Thoracic Surgical Techniques for the Treatment of Spontaneous Pneumothorax. The Journal of Thoracic and Cardiovascular Surgery, 109, 1198-1204. http://dx.doi.org/10.1016/S0022-5223(95)70203-2

[6] Roviaro, G., Varoli, F., Vergani, C. and Maciocco, M. (2002) State of the Art in Thoracoscopic Surgery: A Personal Experience of 2000 Video Thoracoscopic Procedures and an Overview of the Literature. Surgical Endoscopy, 16, 881892. http://dx.doi.org/10.1007/s00464-001-8153-3

[7] Margolis, M., Gharagozloo, F., Tempesta, B., et al. (2003) Video-Assisted Thoracic Surgical Treatment of Initial Spontaneous Pneumothorax in Young Patients. Annals of Thoracic Surgery, 76, 1661-1664. http://dx.doi.org/10.1016/S0003-4975(02)04816-6

[8] Gyorik, S., Erni, S., Studler, U., et al. (2007) Long-Term Follow-Up of Thoracoscopicpleurodesis for Primary Spontaneous Pneumothorax. European Respiratory Journal, 29, 757-760. http://dx.doi.org/10.1183/09031936.00122106

[9] Lang-Lazdunski, L., Chapuis, O., Bonnet, P.M., et al. (2003) Video Thoracoscopic Bleb Excision and Pleural Abrasion for the Treatment of Primary Spontaneous Pneumothorax. Annals of Thoracic Surgery, 75, 960-965. http://dx.doi.org/10.1016/S0003-4975(02)04544-7

[10] Ben-Nun, A., Soudack, M. and Best, L.A. (2006) Video-Assisted Thoracoscopic Surgery for Recurrent Spontaneous Pneumothorax: The Long Term Benefit. World Journal of Surgery, 30, 285-290. http://dx.doi.org/10.1007/s00268-005-0235-2

[11] Passlick, B., Born, C., Sienel, W. and Thetter, O. (2001) Incidence of Chronic Pain after Minimal Invasive Surgery for Spontaneous Pneumothorax. European Journal Cardio-Thoracic Surgery, 19, 335-339. http://dx.doi.org/10.1016/S1010-7940(01)00568-1

[12] Balduyck, B., Hendriks, J., Lauwers, P. and Van Schil, P. (2008) Quality of Life Evolution after Surgery for Primary or 
Secondary Spontaneous Pneumothorax: A Prospective Study Comparing Different Surgical Techniques. Interactive CardioVascular and Thoracic Surgery, 7, 45-49. http://dx.doi.org/10.1510/icvts.2007.159939

[13] Bobbio, A., Ampollini, L., Internullo, E., et al. (2006) Thoracoscopic Parietal Pleural Argon Beam Coagulation versus Pleural Abrasion in the Treatment of Primary Spontaneous Pneumothorax. European Journal Cardio-Thoracic Surgery, 29, 6-8. http://dx.doi.org/10.1016/j.ejcts.2005.10.034

[14] Chan, P., Clarke, P., Daniel, F.J., Knight, S.R. and Seevanayagam, S. (2001) Efficacy Study of Video-Assisted Thoracoscopic Surgery Pleurodesis for Spontaneous Pneumothorax. Annals of Thoracic Surgery, 71, 452-454. http://dx.doi.org/10.1016/S0003-4975(00)02446-2

[15] Ayed, A.K. and Al-Din, H.J. (2000) Video-Assisted Thoracoscopy versus Thoracotomy for Primary Spontaneous Pneumothorax: A Randomized Controlled Trial. Medical Principles and Practice, 9, 113-118. http://dx.doi.org/10.1159/000026127

[16] Waller, D.A., Forty, J. and Morritt, G.N. (1994) Video-Assisted Thoracoscopic Surgery versus Thoracotomy for Spontaneous Pneumothorax. The Annals of Thoracic Surgery, 58, 372-377. http://dx.doi.org/10.1016/0003-4975(94)92210-1

[17] Horio, H., Nomorio, H., Fuyuno, G., Kobayashi, R. and Suemasuk, K. (1998) Limited Axillary Thoracotomy vs. Video-Assisted Thoracoscopic Surgery for Spontaneous Pneumothorax. Surgical Endoscopy, 12, 1155-1158. http://dx.doi.org/10.1007/s004649900805

[18] Czerny, M., Andreas, S., Fleck, T., Hofmann, W., Zimpfer, D., Eckersberger, F., Klepetko, W., Wolner, E. and Mueller, M.R. (1994) Lung Wedge Resection Improves Outcome in Stage I Primary Spontaneous Pneumothorax. The Annals of Thoracic Surgery, 77, 1802-1805. http://dx.doi.org/10.1016/j.athoracsur.2003.10.057

[19] Rivas De Andres, J.J., Freixinet Gilart, J. and Rodriguez De Castro, F. (2002) Spanish Multicenter Study of VideoAssisted Thoracoscopy Surgery. Archivos de Bronconeumología, 38, 60-63.

[20] Hatz, R., Kaps, M., Meimarakis, G., Loehe, F., Muller, C. and Furst, H. (2000) Long-Term Results after Video-Assisted Thoracoscopic Surgery for First-Time and Recurrent Spontaneous Pneumothorax. The Annals of Thoracic Surgery, 70, 253-257. http://dx.doi.org/10.1016/S0003-4975(00)01411-9

[21] Barker, A., Maratos, E.C., Edmonds, L. and Lim, E. (2007) Recurrence Rates of Video-Assisted Thoracoscopic versus Open Surgery in the Prevention of Recurrent Pneumothoraces: A Systematic Review of Randomized and Non-Randomised Trials. The Lancet, 370, 329-335. http://dx.doi.org/10.1016/S0140-6736(07)61163-5

[22] Sawada, S., Watanabe, Y. and Moriyama, S. (2005) Video-Assisted Thoracoscopic Surgery for Primary Spontaneous Pneumothorax: Evaluation of Indications and Long-Term Outcome Compared with Conservative Treatment and Open Thoracotomy. Chest, 127, 2226-2230. http://dx.doi.org/10.1378/chest.127.6.2226

[23] Waller, D.A., Forty, J., Soni, A.K., Conacher, I.D. and Morritt, G.N. (1994) Videothoracoscopic Operation for Secondary Spontaneous Pneumothorax. The Annals of Thoracic Surgery, 57, 1612-1615. http://dx.doi.org/10.1016/0003-4975(94)90133-3

[24] Cardillo, G., Carleo, F., Giunti, R., et al. (2006) Videothoracoscopic Talc Poudrage in Primary Spontaneous Pneumothorax: A Single-Institution Experience in 861 Cases. The Journal of Thoracic and Cardiovascular Surgery, 131, 322328. http://dx.doi.org/10.1016/j.jtcvs.2005.10.025

[25] Ingolfsson, I., Gyllstedt, E., Lillo-Gil, R. Pikwer, A., Jönsson, P. and Gudbjartsson, T. (2006) Reoperations Are Common Following VATS for Spontaneous Pneumothorax: Study of Risk Factors. Interactive CardioVascular and Thoracic Surgery, 5, 602-607. http://dx.doi.org/10.1510/icvts.2006.129676

[26] Uramoto, H., Shimokawa, H. and Tanaka, F. (2012) What Factors Predict Recurrence of a Spontaneous Pneumothorax? Journal of Cardiothoracic Surgery, 7, 112. http://dx.doi.org/10.1186/1749-8090-7-112

[27] Delpy, J.-P., Pagès, P.-B., Mordant, P., Falcoz, P.-E., Thomas, P., Pimpec-Barthes, F.L., Dahan, M. and Bernard, A. for the EPITHOR Project (2016) Surgical Management of Spontaneous Pneumothorax: Are There Anyprognostic Factors Influencing Postoperative Complications? European Journal of Cardiothoracic Surgery, 49, 862-867. http://dx.doi.org/10.1093/ejcts/ezv195

[28] Sihoe, A.D.L., Au, S.S.W., Cheung, M.L., et al. (2004) APC Incidence of Chest Wall Paresthesia after Video-Assisted Thoracic Surgery for Primary Spontaneous Pneumothorax. European Journal of Cardio-Thoracic Surgery, 25, 10541058. http://dx.doi.org/10.1016/j.ejcts.2004.02.018

[29] Jutley, R.S., Khalil, M.W. and Rocco, G. (2005) Uniportal vs Standard Three Port VATS Technique for Spontaneous Pneumothorax: Comparison of Post-Operative Pain and Residual Paraesthesia. European Journal of Cardio-Thoracic Surgery, 28, 43-46. http://dx.doi.org/10.1016/j.ejcts.2005.02.039 


\section{Submit or recommend next manuscript to SCIRP and we will provide best service for you:}

Accepting pre-submission inquiries through Email, Facebook, LinkedIn, Twitter, etc.

A wide selection of journals (inclusive of 9 subjects, more than 200 journals)

Providing 24-hour high-quality service

User-friendly online submission system

Fair and swift peer-review system

Efficient typesetting and proofreading procedure

Display of the result of downloads and visits, as well as the number of cited articles

Maximum dissemination of your research work

Submit your manuscript at: http://papersubmission.scirp.org/ 